\title{
A Brief Update on Intelligence in Autism Spectrum Disorders
}

\author{
Laura 0 Saad* and Eloisa H R V Celeri \\ Department of Medical Psychology and Psychiatry, Brazil
}

Submission: January 31, 2018; Published: February 05, 2018

*Corresponding author: Laura O Saad, Department of Medical Psychology and Psychiatry Medical School, State University of Campinas(Unicamp), Brazil, Tel: +55 (19) 3521-7206; Email: laura.saa@gmail.com

\begin{abstract}
Autism Spectrum Disorders (ASD) and Intellectual Disability have been commonly associated with prevalence rates of comorbidity being around $70 \%$. However, in the last few years, not only these rates have been dropping, but also research is experiencing a great shift regarding intelligence in ASD individuals. Here the authors provide a brief state-of-the-art update on what is changing and try to foresee future directions. Keywords: Autism spectrum disorders; Intellectual disability; Child and adolescent psychiatry
\end{abstract}

\section{Introduction}

Autism spectrum disorders (ASD) share features of impaired social-communicative interactions, focused interest and repetitive behaviors. Intellectual disability (IQ score $<70$ ) is commonly associated with ASD. Historically, the prevalence rates were around $70 \%$ of autistic individuals with intellectual disability [1]. But these rates have been dropping in the last decade. According to the CDC, in 2012, the prevalence of autistic children with intellectual disability was $31.6 \%, 24.5 \%$ were on the borderline range (IQ: 70-85) and 43.9\% were classified in the average and above average range (IQ>85) [2]. This finding is not limited to the US, in the United Kingdom corresponding prevalence rates have been reported as well [3]. Although changes in awareness and clinical practice, driven by the evolving definition of the disorder, are probably underlying this process, there are other important factors that should be taken into account. As scientific knowledge expands, genetic studies have gained increased importance in understanding the disorder.

The genetic link between Intellectual Disability and ASD is not clear. Certain genetic syndromes (Fragile X, Rett, Tuberous Sclerosis, Down, phenylketonuria, CHARGE, and Angelman) are associated with severe Intellectual Disability and also have a high incidence of ASD [4,5]. There is evidence linking genes of intellectual disability, ASD epilepsy and schizophrenia [6-8]. However, in a study conducted by Hoekstra and colleagues [9] the genetic correlation between autistic traits and intellectual disability was only modest. And, other studies have reported significant overlap between the alleles that are associated with high intelligence [10] and educational level (strongly correlated to intelligence) and autism risk [11,12], among neuro typical individuals.

Another interesting finding in the last few years in the research field concerning intelligence in autistic individuals is that it may be underestimated. Early descriptions and quantifications of their intelligence highlight the discrepancy of their abilities [13]. Findings of strong performance on specific tests have been considered abnormal areas of abilities emerging from a multitude of deficiencies $[14,15]$. But, since autism is characterized by atypical information processing due to sensorial abnormalities, researchers have questioned their evaluation methods. A handful of studies have compared individuals with ASD performances on Wechsler scales of intelligence and Raven's Progressive Matrices (RPM) [3,16-18]. RPM is a test that minimizes spoken instruction and avoids speech production [19].

It is regarded as the best marker of fluid intelligence, which comprehends abilities to reason and novel problem-solving [20]. While typical individuals display similar performance in both tests, for autism that is not upheld, with consistent findings reporting advantages in RPM scores compared to Wechsler scores. These results have even been reported for individuals with Asperger's Syndrome, who have less impairment in socialcommunicative behaviors [21]. A third important factor that should be considered is that the cognitive profile of autistic children can change through time. A few studies have shown that IQ increases in ASD children from early to middle childhood $[22,23]$, with comparable development between non-verbal 
IQ and verbal IQ [24]. One study followed the developmental trajectories of ASD children between ages 2 and 8 years of age and reported almost $57 \%$ of participants presenting improvements in IQ measures through time [25].

\section{Conclusion}

While there is still a lot to understand regarding autism and intelligence, a growing body of literature has currently started pointing to a different direction than previously consolidated. As the research field advances, prevalence rates of autism co morbid with intellectual disability tend to decrease not only because of new definition parameters. The methods of evaluating intelligence in these individuals should be revised, leading to perhaps more drops in these rates. Crespi, recently, hypothesized that autism might be a disorder of high intelligence, but with imbalanced components [26]. It is not possible to confirm this theory yet, but it emphasizes the great shift the area has been having the last few years.

\section{References}

1. Fombonne E (2006) Past and future perspectives on autism epidemiology. In Understanding Autism, from Basic Neuroscience to Treatment (eds SOMoldin, JLR Rubenstein): 25-48 Taylor \& Francis.

2. Christensen DL, Jon Baio, Braun KVN, Bilder D, Charles J, et al. (2016) Prevalence and Characteristics of Autism Spectrum Disorder Among Children Aged 8 Years- Autism and Developmental Disabilities Monitoring Network, 11 Sites, 2012, CDC United States, USA.

3. Charman T, Pickles A, Simonoff E, Chandler S, Loucas T, et al. (2011) IQ in children with autism spectrum disorders: data from the Special Needs and Autism Project (SNAP). Psychological Medicine 41: 619627.

4. Belmonte MJ, Bourgeron T (2006) Fragile X syndrome and autism at the intersection of genetic and neural networks. Nature Neuroscience 9(10): 1221-1225.

5. Dykens EM, Sutcliffe JS, Levitt P (2004) Contrasting autism and 15q11-q13 disorders: Behavioral, genetic and pathophysiological issues. Mental retardation and developmental disability research reviews 10: 284-291.

6. Mefford HC, Cooper GM, Zerr T, Smith JD, Baker C, et al. (2009) A method for rapid, targeted CNV genotyping identifies rare variants associated with neuro cognitive disease. Genome Res 19: 1579-1585.

7. Ullmann R, Turner G, Kirchhoff M, chen W, tonque B, et al. (2007) Array CGH identifies reciprocal 16p13. 1 duplications and deletions that predispose to autism and/or mental retardation. Hum Mutat 28: 674-82.

8. Mefford HC, Batshaw ML, Hoffman EP (2012) Genomics, Intellectual Disability, and Autism. N Engl J Med 366(8): 733-743.

9. Hoekstra RA, Happe F, Baron Cohen S Ronald A (2009) Association between extreme autistic traits and intellectual disability: insights from a general population twin study. British J of Psychiatry 195: 531536.
10. Clarke TK, Lupton MK, Fernandez Pujals AM, Starr J, Davies G, et al. (2015) Common polygenic risk for autism spectrum disorder (ASD) is associated with cognitive ability in the general population Mol Psychiatry 21: 419-425.

11. Bulik Sullivan B, Finucane HK, Anttila V, Gusev A, Day FR, et al. (2015) An atlas of genetic correlations across human diseases and traits. Nat Genet 47: 1236-1241.

12. Hill WD, Davies G, Charge Cognitive Working Group, Liewald DC, McIntosh AM, et al. (2015) Age-dependent pleiotropy between general cognitive function and major psychiatric disorders. Biol.Psychiatry 80(4): 266-273.

13. Rutter M (1966) Behavioral and cognitive characteristics of a series of psychotic children. In: Wing L, ed. Early childhood autism: Clinical, educational and social aspects. Oxford: Pergamon Press pp. 51-81.

14. Happe F (1994) Wechsler IQ profile and theory of mind in autism: a research note. Journal of Child Psychology and Psychiatry and allied disciplines 35(8): 1461-1471.

15. Shah A, Frith U (1993) why do autistic individuals show superior performance on the block design task? Journal of Child Psychology and Psychiatry 34: 1351-1364.

16. Dawson M, Soulières I, Gernsbacher MA, Mottron L (2007) The level and nature of autistic intelligence. Psychological Science 18(8): 657662.

17. Bolte S, Dziobek I, Poustka F (2009) Brief report: The level and nature of autistic intelligence revisited. Journal of Autism and Developmental Disorders 39(4): 678-682.

18. Morsanyi K, Holyoak KJ (2010) Analogical reasoning ability in autistic and typically developing children. Developmental Science 13: 578-587.

19. Raven J, Raven JC, Court JH (1998) Standard Progressive Matrices. Raven Manual: Section 3. Oxford: Oxford Psychologists Press, USA.

20. Mackintosh NJ (1998) IQ and human intelligence: Oxford University Press. IQ and human intelligence ix 419, New York NY, USA.

21. Soulières I, Dawson M, Gernsbacher MA, Mottron L (2011) The level and nature of autistic intelligence II: What About Asperger Syndrome? PLoS One 6: 1-7.

22. Flanagan HE, Smith IM, Vaillancourt T, Duku E, Szatmari P, et al. (2015) Stability and change in the cognitive and adaptive behavior scoresof preschoolers with autism spectrum disorder. Journal of Autism and Developmental Disorders 45: 2691-2703.

23. Turner LM, Stone WL, Pozdol SL, Coonrod EE (2006) Follow-up of children with autism spectrum disordersfrom age 2 to age 9 . Autism 10(3): 243-265.

24. Anderson DK, Liang JW, Lord C (2013) Predicting young adult outcome among more and less cognitively able individuals with autism spectrum disorders. Journal of Child Psychology and Psychiatry 55(5): 485-494.

25. Solomon M, Iosif Ana Maria, Reinhardt VP, Libero LE, Nordahl CW, et al. (2018) What will My Child's Future Hold? Phenotypes of Intellectual Development in 2-8-Year-Olds with Autism Spectrum Disorder. Autism Res 1: 121-132.

26. Crespi BJ (2016) Autism as a disorder of high intelligence. Frontiers in Neuroscience 10: 1-17. 

(C) This work is licensed under Creative BY DOI: 10.19080/GJIDD.2018.04.555637
Your next submission with Juniper Publishers will reach you the below assets

- Quality Editorial service

- Swift Peer Review

- Reprints availability

- E-prints Service

- Manuscript Podcast for convenient understanding

- Global attainment for your research

- Manuscript accessibility in different formats

( Pdf, E-pub, Full Text, Audio)

- Unceasing customer service

Track the below URL for one-step submission https://juniperpublishers.com/online-submission.php 